\title{
PRIMAVERAS TRÁGICAS, REBELIONES MILITARES Y TERRORES ROJOS EN ESPAÑA. LA VIOLENCIA POLÍTICA DE 1936 EN LA PROVINCIA DE GUADALAJARA
}

\author{
TRAGIC SPRINGS, MILITARY REBELLIONS \\ AND RED TERRORS IN SPAIN. POLITICAL VIOLENCE \\ IN 1936 IN THE PROVINCE OF GUADALAJARA
}

Isaac Martín Nieto*

Universidad de Santiago de Compostela, España

\begin{abstract}
RESUMEN: Este artículo examina la violencia política desplegada en España durante 1936 usando la provincia de Guadalajara como ejemplo. El objetivo consiste en averiguar si hubo conexiones o no entre las acciones colectivas anteriores y posteriores a la rebelión militar del 18 de julio. Primero, relata y analiza la movilización social y política desarrollada durante la primera mitad del año. Después, describe y estudia la violencia política del resto del año. Las tesis principales del artículo sostienen que la violencia política no fue un factor determinante del proceso político durante los primeros seis meses y medio de 1936, que no hubo continuidad alguna entre la violencia política anterior y posterior al inicio de la guerra y que la conflictividad social y política previa a la guerra fue solo uno de los varios factores que explican la violencia política que siguió a la insurrección militar.
\end{abstract}

PALABRAS CLAVE: violencia política, España, Guadalajara, Segunda República, guerra civil española.

ABSTRACT: This article examines the political violence deployed in Spain during 1936 using the province of Guadalajara as a case study. Its objective is to clarify whether collective actions before and after the military rebellion of the 18th of July were connected. Firstly, it recounts and analyses the social and political mobilization that took place during the first half of the year. Then, it describes and studies the political violence deployed during the rest of the year. The article argues that political violence was not a determining factor in the political process during the first six and a half months of 1936, that there was not any continuity between political violence before and after the beginning of the war, and that the social and political unrest prior to that war was only one of the various reasons which explain the political violence subsequent to the military insurrection.

KEYWORDS: political violence, Spain, Guadalajara, Spanish Second Republic, Spanish Civil War.

* Correspondencia a: Isaac Martín Nieto. Departamento de Historia, Facultade de Xeografía e Historia, Universidade de Santiago de Compostela, Praza da Universidade, 1, 15782 Santiago de Compostela - isaac.martin@usc.es - http://orcid. org/0000-0002-9565-0385

Cómo citar: Martín Nieto, Isaac (2021). « Primaveras trágicas, rebeliones militares y terrores rojos en España. La violencia política de 1936 en la provincia de Guadalajara»; Historia Contemporánea, 66, 465-492. (https://doi.org/10.1387/hc.21208).

Recibido: 31 octubre, 2019; aceptado: 14 febrero, 2020.

ISSN 1130-2402 - eISSN 2340-0277 / (C) 2020 UPV/EHU

(c) (i) $\odot$ Esta obra está bajo una Licencia

Cy Creative Commons Atribución-NoComercial-SinDerivadas 4.0 Internacional 
El día 5 de enero hubo en Auñón, una localidad situada al suroeste de la provincia de Guadalajara, un choque violento entre socialistas y católicos motivado por el control del ayuntamiento que se saldó con varios individuos detenidos, dos heridos y una víctima mortal, un militante católico llamado Mariano Martínez Fernández, tiroteado por el alcalde electo, que había sido destituido por una comisión gestora conservadora. El 11 de marzo un simpatizante del Frente Popular, Víctor Bernáldez, que era cartero en Moratilla de los Meleros, no muy lejos de Auñón, murió víctima de una colisión violenta entre vecinos del pueblo. El 13 de junio un grupo de falangistas mató al socialista Francisco González durante un intento de asalto a la Casa del Pueblo de Guadalajara capital. Y en la noche del 13 al 14 de julio en Sigüenza, al norte del territorio provincial, un grupo de pistoleros falangistas asesinó al presidente de la Casa del Pueblo, Francisco Gonzalo de Francisco, cartero, fundador de la Agrupación Socialista y del Sindicato de Oficios Varios y presidente, también, de la Comisión Gestora del Ayuntamiento. Y eso es todo. Esos son todos los episodios de violencia política con resultado de muerte que hubo durante los seis meses y medio de 1936 que transcurrieron antes de que empezara la guerra civil ${ }^{1}$.

Hubo otros casos no carentes de gravedad, ciertamente, pero ninguno terminó con víctimas mortales. Durante la campaña electoral los izquierdistas reventaron varios actos derechistas en siete municipios de la provincia, en los partidos de Brihuega, Cifuentes, Pastrana y Molina de Aragón, y los derechistas hicieron lo propio con algunos actos izquierdistas en dos municipios, distritos de Cogolludo y Molina. Tras el desfile del 14 de abril en Guadalajara capital, protagonizado por los soldados del Regimiento de Aerostación y los números de la Guardia Civil, se produjeron algunos enfrentamientos entre partidarios del Frente Popular y grupos de derechistas. La manifestación que se organizó posteriormente apedreó el Casino y obligó a algunos comercios a cerrar. El gobernador, Miguel Benavides, ordenó una veintena de detenciones, entre falangistas, tradicionalistas y cedistas, y la clausura del Centro tradicionalista y el Centro Obrero Católico. En Pastrana una manifestación de mujeres amenazó con

1 Auñón, en Abril, 18 de enero de 1936, p. 2 (si no se indica lo contrario siempre será Abril y 1936, por lo que a partir de ahora solo mencionaré el día, el mes y la página) y Álvarez Tardío, 2013, p. 482. Moratilla, en 21 de marzo, p. 1. Sigüenza, en 18 de julio, pp. 1 y 4. Guadalajara, en González Calleja, 2015, p. 418. En este libro hay asimismo breves reseñas de los otros tres incidentes violentos. Ver pp. 392 (Auñón), 401-402 (Moratilla) y 423 (Sigüenza). 
atacar a la inspectora Tomasa Piosa, que acababa de clausurar el Colegio las Religiosas. Para disolver la manifestación y proteger a la funcionaria el alcalde tuvo que solicitar la intervención de esa misma institución. En La Olmeda de Jadraque un cabo y dos números de la Guardia Civil hirieron a tres personas el 3 de junio al tirotear a un grupo de campesinos afectos a la Casa del Pueblo que pretendía impedir que las salinas situadas en el término municipal fueran trabajadas por obreros procedentes de otra población. Y en Brihuega un grupo de extremistas de derecha asaltó el ayuntamiento el 14 de abril. También hubo varios episodios de violencia anticlerical. En Horche se produjo el 17 de febrero el asalto y el saqueo de una ermita y el robo de la imagen. En Riba de Saelices también asaltaron y saquearon una ermita el día 19 de marzo, aunque aquí las imágenes fueron quemadas directamente. Y en mayo fueron asaltadas y ocupadas las casas rectorales de Ciruelos del Pinar y Tordesilos ${ }^{2}$.

A la vista de este breve relato de los actos violentos de naturaleza política y social ocurridos en la provincia de Guadalajara antes de la sublevación militar resulta sorprendente la magnitud de lo que ocurrió después de la misma. Y es que el fracaso de esa rebelión abrió las puertas a una etapa caracterizada por la violencia política, no solo en virtud de la guerra civil que desató el triunfo de esa sublevación en media España, sino, sobre todo, por el proceso revolucionario violento que impulsaron los partidos y sindicatos de la izquierda obrera. Durante los cerca de tres años que duró la guerra esa violencia política acabó con la vida de al menos 709 personas residentes en municipios de la provincia. Este trabajo tiene el propósito de contribuir al debate sobre las continuidades y rupturas que representó la rebelión militar de julio de 1936 en el plano de la violencia sociopolítica desde la atalaya de un territorio como el de Guadalajara, que tras el golpe de Estado fallido recibió el impacto de un inesperado y violento proceso revolucionario a pesar de haber sido una provincia relativamente pacífica. La estrategia para llegar a conclusiones válidas para el general consistirá, primero, en relatar y analizar la movilización social y política desplegada durante el invierno, la primavera y la primera parte del verano de 1936; segundo, en describir y ana-

2 Actos electorales, en 22 de febrero, p. 4, y Díez Torre, 1983, pp. 144-145. Guadalajara, en 18 de abril, pp. 1 y 3. Pastrana, en 23 de mayo, p. 1. La Olmeda, en 13 de junio, p. 4. Brihuega, en 16 de mayo, p. 1, e Ibid., p. 162. Violencia anticlerical, en Álvarez Tardío y Villa García, 2013, p. 734; el acontecimiento de Horche, también en 22 de febrero, p. 3 . 
lizar la violencia revolucionaria desarrollada en la provincia durante la segunda mitad del verano y el otoño de ese mismo año; y tercero, en establecer conexiones entre las acciones colectivas de antes y de después de julio ${ }^{3}$.

Antes de entrar de lleno en los relatos y los análisis, me parece de justicia realizar un par de advertencias preliminares. La primera es que el análisis de la violencia política posterior a la sublevación militar está centrado exclusivamente en la zona republicana. Y es que buena parte de esta provincia permaneció bajo control de las tropas rebeldes desde el principio de la guerra. La cuestión es, sin embargo, que falta todavía una investigación que desentrañe el origen, la naturaleza y los fines de la violencia política en la zona rebelde. Ni que decir tiene que tampoco existe un cálculo mínimamente fiable de la cifra de víctimas provocadas por esa violencia. Lo único que hoy en día puede ser tomado como punto de partida es el guarismo que ofreció hace ya más de cuarenta años Ramón Salas Larrazábal en su Pérdidas de la guerra: 789 personas asesinadas o ejecutadas. Una cifra, sin embargo, insuficiente para ampliar el análisis a todo el territorio provincial en la medida en que resulta imposible desagregarla en términos espaciales y temporales. La segunda advertencia es que la reconstrucción de la movilización social y política desplegada en esta provincia durante los primeros siete meses de 1936 que ofrezco aquí está muy lejos de ser definitiva debido a la escasez y parcialidad de la base documental sobre la que está levantada. De hecho, para esa reconstrucción solo he podido utilizar el semanario Abril, un periódico editado desde 1935 en la capital provincial por republicanos, socialistas y comunistas. Siempre que ha sido posible, la información procedente de ese pe-

${ }^{3}$ Un buen resumen de ese debate, en Ledesma, 2013, pp. 313-339. La cifra de víctimas de la violencia es propia y ha sido obtenida a partir de los datos de la Causa General de la provincia de Guadalajara, conservada en el Archivo Histórico Nacional, aunque puede consultarse en el Portal de Archivos Españoles, PARES, pares.mcu.es [6 de agosto de 2020]. Para una mayor información sobre las fuentes y la metodología utilizadas en este recuento provisional, ver Martín Nieto, 2014, pp. 31-32 y nota 5. En el citado artículo ofrecí un número de muertes violentas que he podido actualizar para este trabajo: la cifra ha pasado de 706 a 709. Toda la información relativa a las víctimas de la violencia que utilizo aquí procede de mi propia base de datos. La perspectiva teórica desde la que analizo tanto las acciones colectivas anteriores a la sublevación militar como las posteriores a la misma es la propia de los analistas de los movimientos sociales. Mis referencias fundamentales son Tarrow, 1997, y la introducción y los capítulos conceptuales de McAdam, McCarthy y Zald, 1999. 
riódico ha sido contrastada y completada con la del artículo de Alejandro Díez Torre sobre la crisis del sistema caciquil en esta provincia ${ }^{4}$.

\section{La conflictividad social y política entre enero y julio}

Durante el invierno, la primavera y las primeras semanas del verano de 1936 en esta provincia se desplegaron amplias campañas de propaganda electoral por parte de republicanos, socialistas y comunistas, se plantearon largas y enconadas huelgas industriales y agrarias y se produjeron también multitudinarias concentraciones y manifestaciones de campesinos y obreros. Prácticas políticas y sindicales todas que representaban un claro desafío a la hegemonía política y social que liberales y católicos disfrutaban en Guadalajara desde antes de la instauración de la República. Una hegemonía que había quedado claramente demostrada con los resultados de las elecciones de noviembre de 1933 y febrero de 1936 tras el espejismo del triunfo de los representantes de la conjunción republicano-socialista en junio de 1931. En efecto, los candidatos que obtuvieron el acta de diputado por esta provincia en los comicios de febrero fueron dos liberales, Álvaro Figueroa y Torres, conde de Romanones, y su hijo, Álvaro Figueroa y Alonso Martínez, y dos católicos, José Arizcun Moreno y Félix Valenzuela, ambos en nombre de la CEDA. Las derechas salieron victoriosas en todos los partidos judiciales de la provincia y en todos los distritos fueron mayoría los municipios que otorgaron el triunfo a las derechas (cuadro 1 y mapa 1). Buena parte de los mítines celebrados para apoyar la candidatura izquierdista en las elecciones de febrero tuvieron lugar en municipios de la zona suroccidental de la provincia, en los partidos de Guadalajara y Pastrana. Aunque también se celebraron muchos actos de este tipo en las áreas septentrional y oriental de la provincia, en los partidos de Atienza, Molina y Sigüenza 5 .

4 Salas Larrazábal, 1977, citado en Ortiz Heras, 2008, p. 1388. Hay disponible una colección incompleta del semanario Abril en la web de la Biblioteca Virtual de Prensa Histórica del Ministerio de Educación, Cultura y Deporte, prensahistorica.mcu.es [6 de agosto de 2020]. El artículo es Díez Torre, 1983.

5 Elecciones, en Requena Gallego, 1988, p. 31; y Boletín Oficial de la Provincia de Guadalajara, 27 de noviembre de 1933, pp. 5-15, y 24 de febrero de 1936, pp. 3-10. Mítines, en 21 de diciembre de 1935 , p. 2; 11 de enero, p. 1; 5 de febrero, p. 2; 11 de febrero, p. 2; 15 de febrero, p. 2; y Díez Torre, 1983, pp. 144-145. 


\section{Cuadro 1}

Resultados electorales de febrero de 1936 por partidos judiciales

\begin{tabular}{lccccc}
\hline \multicolumn{1}{c}{ Partidos judiciales } & Derechas & Porcentaje & Izquierdas & Porcentaje & Total \\
\hline Atienza & 12.509 & 65,29 & 6.650 & 34,71 & 19.159 \\
Brihuega & 19.382 & 76,78 & 5.863 & 23,22 & 25.245 \\
Cifuentes & 14.946 & 69,21 & 6.650 & 30,79 & 21.596 \\
Cogolludo & 14.185 & 73,50 & 5.115 & 26,50 & 19.300 \\
Guadalajara & 22.405 & 60,52 & 14.613 & 39,48 & 37.018 \\
Molina de Aragón & 29.928 & 64,33 & 16.596 & 35,67 & 46.524 \\
Pastrana & 27.830 & 81,49 & 6.323 & 18,51 & 34.153 \\
Sacedón & 15.780 & 83,10 & 3.209 & 16,90 & 18.989 \\
Sigüenza & 15.664 & 57,91 & 11.385 & 42,09 & 27.049 \\
\hline Total & 172.629 & 69,32 & 76.404 & 30,68 & 249.033 \\
\hline
\end{tabular}

Fuente: Boletín Oficial de la Provincia de Guadalajara, 24 de febrero de 1936, pp. 3-10.

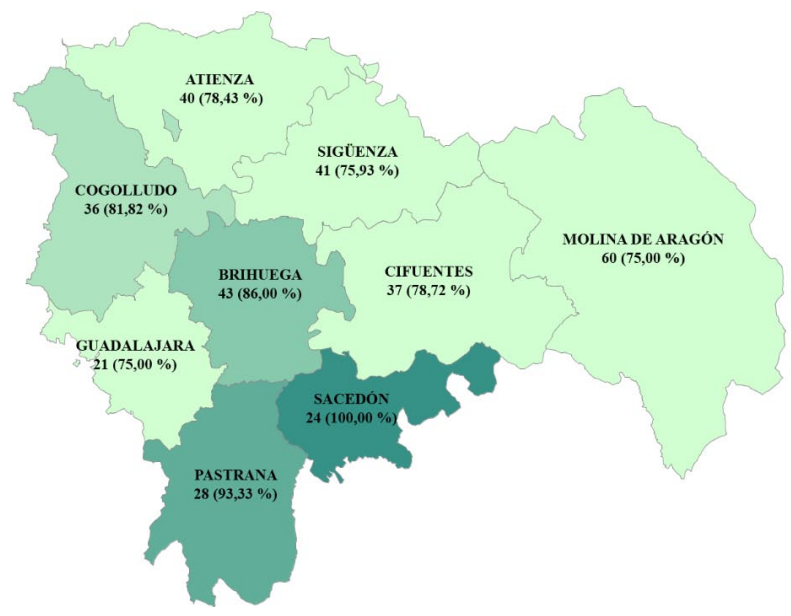

\section{Mapa 1}

Municipios con mayoría derechista en las elecciones de 1936 por partidos judiciales

Fuente: Boletín Oficial de la Provincia de Guadalajara, 24 de febrero de 1936, pp. 3-10. 
La zona de la provincia que conoció un mayor nivel de conflictividad laboral durante los meses anteriores a la rebelión militar fue el partido de Guadalajara. Cuando los soldados y guardias civiles de la capital provincial salieron a la calle el 21 de julio todavía estaban en huelga los obreros que trabajaban en la fábrica de cemento conocida como la Pizarrita. La habían planteado a primeros de mayo para reivindicar un aumento de salario y una mejora en las condiciones de trabajo relacionada con la salud del personal empleado. Pero la intensa conflictividad laboral que afectó a esta zona de la provincia no se redujo a la capital provincial. De hecho, fue en algunos municipios de este partido donde mayor impacto tuvo la huelga planteada en toda la provincia por los obreros del campo. Fue convocada a finales de junio por la Federación Provincial de Trabajadores de la Tierra de la UGT con el propósito de obligar al Jurado Mixto Rural a contemplar en su dictamen las bases de trabajo elaboradas en el congreso que esa organización había celebrado el 7 de mayo. Esencialmente reivindicaban un aumento de salario, una disminución de la jornada y la creación de bolsas de trabajo en las Casas del Pueblo para los socios de la UGT y la CNT. La huelga consiguió pronto sus objetivos, pero como los jornales habían sido vinculados al rendimiento del trabajo, el conflicto rebrotó rápidamente a principios de julio. Cuando la rebelión militar comenzó no existía aún acuerdo alguno entre propietarios y jornaleros ${ }^{6}$.

Las acciones colectivas preferidas por los diversos actores sociales y políticos no fueron, sin embargo, las huelgas, sino las concentraciones, las manifestaciones y los mítines. De este tipo de acciones hubo por todo el territorio, pero la mayor parte tuvo lugar en dos zonas separadas. La primera comprendía los partidos de Guadalajara y Sacedón; la segunda, los de Molina y Sigüienza. Las primeras multitudes que ocuparon la calle tras los comicios de febrero fueron los sectores de la ciudadanía que celebraban la victoria a nivel nacional de la coalición del Frente Popular. Cuatro días después de las elecciones los manifestantes liberaron de la prisión de la capital provincial a tres guardias de asalto pertenecientes a las milicias socialistas y condenados por su participación en la insurrección revolucionaria de octubre de 1934. Acto seguido la mani-

${ }^{6}$ La huelga de la Pizarrita, en 16 de mayo, p. 1; 23 de mayo, p. 1; 30 de mayo, pp. 1 y 2; 6 de junio, p. 2; 13 de junio, p. 2; 20 de junio, p. $3 ; 27$ de junio, pp. 1 y 2 ; y 11 de julio, p. 3. La huelga agrícola, en 16 de mayo, p. 4; 27 de junio, pp. 1 y 4; 4 de julio, p. 1; 11 de julio, pp. 1 y 4 . Ver, también, ibid., pp. 159-161. 
festación ocupó el ayuntamiento y constituyó una comisión gestora que pretendía recomponer la corporación municipal elegida el 12 de abril de 1931. En los días siguientes hubo manifestaciones que celebraron el triunfo electoral izquierdista en otras localidades de la provincia, pero la acción más significativa de este tipo fue la que los partidos y sindicatos izquierdistas organizaron el 1 de marzo en la capital de la provincia para exigir al Gobierno el cumplimiento del pacto electoral. Las 4.000 personas que asistieron a esa manifestación pudieron después escuchar los discursos del gobernador civil, el alcalde y el presidente de la Federación Obrera de la UGT ${ }^{7}$.

La mayor parte de las manifestaciones celebradas en la provincia durante los meses siguientes sirvieron para reclamar el rescate de los bienes comunales, la explotación de las grandes propiedades de tierra sin cultivar y la promulgación de una ley de arrendamientos. Estas acciones colectivas alcanzaron mayor amplitud en los partidos de Sacedón, Sigüenza, Molina y Cifuentes. En buena parte de las localidades de esas zonas de la provincia las manifestaciones que celebraban la Fiesta del Trabajo del Primero de Mayo terminaron con la petición de que las tierras privatizadas que habían pertenecido a los municipios fueran devueltas a sus anteriores titulares. Así ocurrió en varios pueblos de los distritos de Sacedón y Sigüenza. Acciones colectivas de esta naturaleza hubo también a lo largo de los meses de marzo, abril y mayo en otros municipios de los partidos de Molina, Sacedón y Sigüenza. Pero donde estas movilizaciones tuvieron mayor éxito y grado de organización fue en la zona del Ducado de Medinaceli, en poblaciones pertenecientes a los partidos de Cifuentes, Molina y Sigüenza en las que los montes públicos habían sido en buena parte privatizados por la Unión Resinera Española. Aquí las manifestaciones resultaron en la formación de un Comité Regional pro-rescate, orbitaron en torno al Sindicato Resinero de Mazarete y culminaron con la celebración de una masiva concentración de campesinos en esa localidad el 4 de junio ${ }^{8}$.

722 de febrero, pp. 1 y 2; 29 de febrero, pp. 2 y 4; y 7 de marzo, p. 1 . Más manifestaciones, en 7 de marzo, pp. 3 y 4.

86 de junio, pp. 1 y 3 . El rescate de bienes comunales estaba entre las conclusiones aprobadas por la Federación Provincial de Trabajadores de la Tierra en los dos congresos que celebró en enero y mayo de 1936 . Ver 18 de enero, p. 4; y 16 de mayo, p. 4. Más sobre estas movilizaciones campesinas, en 21 de marzo, p. 4; Díez Torre, 1983, p. 152; e íd., 1984, pp. 183-184. 
Los campesinos de la provincia también reclamaban la explotación de aquellas fincas que habían dejado de ser arrendadas y no estaban siendo cultivadas directamente por sus propietarios. En otras palabras, solicitaban la aplicación del decreto sobre laboreo forzoso de mayo de 1931, convertido en ley en septiembre del mismo año. En esa situación había importantes extensiones de terreno que eran de señorío, como en El Pobo de Dueñas, donde la manifestación que tuvo lugar el 8 de marzo terminó pidiendo al ayuntamiento que las tierras del señorío de Molina que había en el término municipal fueran puestas en cultivo inmediatamente. Se trataba de acciones que se concentraban por lo general en el partido de Molina, como las de los campesinos que exigían la promulgación de una ley que regulara el acceso a la propiedad, la supresión de impuestos y la concesión de créditos. Eran en su mayoría vecinos de localidades comprendidas en ese partido que aprovecharon las conmemoraciones del 14 de Abril y el Primero de Mayo para expresar sus reclamaciones en público 9 .

Porque era precisamente entonces cuando todas las reivindicaciones sostenidas por republicanos, socialistas y comunistas encontraban su sitio en la calle. Los vecinos de los pueblos solían viajar a la cabecera del partido u otra población de referencia para formar en manifestaciones multitudinarias. Y no hubo otra más multitudinaria que la que recorrió las calles de la capital provincial el 1 de mayo para entregar sus reivindicaciones al gobernador civil. Antes de eso dirigentes de la Federación Obrera, las Juventudes Socialistas Unificadas, el PSOE y el PCE hablaron ante más de 5.000 personas en un mitin que tuvo lugar en la Plaza de Toros de la ciudad. A las manifestaciones y mítines del Primero de Mayo en Molina y Sigüenza asistieron representantes de las localidades de la zona. En la primera hubo miles de personas, todas procedentes de localidades del partido. A la de Sigüenza, que fue acompañada de una velada teatral, concurrieron vecinos de poblaciones del propio partido de Sigüenza y de otras de los partidos de Atienza y Cifuentes. También hubo manifestaciones en otras localidades del partido de Molina, que fueron, en algunos casos, combinadas con rondallas y bailes. Aunque menos sonadas que las manifestaciones de los partidos de Guadalajara, Molina y Sigüenza, las celebradas en el resto de la provincia supusie-

9 El Pobo y otras localidades, en 21 de marzo, p. 2; 13 de junio, p. 1; y Díez Torre, 1983, p. 154. El resto, en 25 de abril, p. 2; e ibid., pp. 155-156. 
ron, igualmente, un notorio desafío a la hegemonía liberal y conservadora $^{10}$.

\section{La violencia política entre julio y diciembre}

La neutralización de la sublevación militar en la ciudad de Guadalajara fue inmediatamente seguida de la movilización armada de las organizaciones de la izquierda burguesa y obrera tanto en la capital como en el resto de la provincia. Los militares y guardias civiles que salieron a la calle el día 21 de julio de 1936 tomaron el control de las calles de la capital con relativa facilidad. Pero al día siguiente los rebeldes fueron derrotados por la columna del coronel Ildefonso Puigdengolas, procedente de Madrid y compuesta por militares, guardias de asalto y milicianos. A partir de entonces la ciudad estuvo bajo la autoridad de un Comité del Frente Popular compuesto por socialistas, comunistas y republicanos y los pueblos, bajo la de los comités de enlace formados por los líderes de los diversos partidos y sindicatos de izquierda. Esos poderes revolucionarios procedieron de forma inmediata a la movilización de los militantes de las organizaciones políticas y sindicales de izquierda, al reclutamiento de grupos de civiles armados y al ejercicio de las funciones policiales y judiciales que hasta entonces habían sido potestad del Estado republicano, maltrecho por el impacto sucesivo del golpe de Estado militar, primero, y de la movilización armada de la población civil, después ${ }^{11}$.

Los siete centenares de víctimas mortales que hubo en esta provincia durante la guerra civil fueron en su mayoría el resultado de la acción combinada de los grupos de milicianos y de los comités locales. Los primeros ostentaban las armas. Los segundos poseían la información. De no haber

109 de mayo. Guadalajara capital, en 2 de mayo, pp. 1,2 y 4. Más manifestaciones, mítines, rondallas y bailes, en 18 de abril, pp. 1 y $3 ; 25$ de abril, p. 2 ; y 2 de mayo, pp. 2 y 4. Otros mítines, en 4 de abril, p. 1, y 18 de julio, p. 2 (unión antifascista); 23 de mayo, p. 2 (alianza obrera; antes hubo manifestación); y 6 de junio,p. 1 (educación). Concentración y mitin, en 4 de julio, p. 2; e ibid., p. 159 (programa del Frente Popular, huelgas agrícolas y rentas de los arrendatarios).

${ }^{11}$ El desarrollo de la rebelión militar, en Salas Larrazábal, 1973, vol. I, pp. 248-251; y Camarena Merino, 2000, pp. 116-120. El Comité del Frente Popular, en Archivo Histórico Nacional. Causa General (a partir de ahora: AHN. CG), legajo 1.552, exp. 3, f. 471; los comités de los pueblos, en legajo 1.071, exp. 111. 
existido colaboración entre milicianos y comités es probable que no hubiera habido tantas víctimas de la violencia. Los milicianos no habrían sabido a quién matar y los comités no habrían podido fusilar a tantos. Ahora bien, creo que no conviene exagerar la responsabilidad en la violencia política de los grupos de milicianos extraños a la comunidad. O al menos no conviene hacerlo en el caso de esta provincia, como habrá ocasión de comprobar enseguida. En cualquier caso, de lo que no cabe duda es de que fueron los milicianos y los comités los que acabaron con la vida de la mayor parte de las víctimas de la violencia de esta provincia. La cronología de asesinatos y ejecuciones no deja lugar a la duda ${ }^{12}$.

De las 709 personas que fueron muertas violentamente durante la guerra por motivos políticos, 639 perdieron la vida antes de que acabara el año. Ni que decir tiene que las cifras correspondientes a los otros tres años de guerra no fueron nada en comparación con ese 90 por 100 del total. En 1937 hubo 48 muertes, menos del 7 por 100 del total, en 1938 murieron 18 personas y en 1939 solo 4 (gráfico 1). Es decir, que la inmensa mayoría de los asesinatos y ejecuciones se produjo durante los primeros seis meses de guerra, que fueron los que duró la situación de soberanía múltiple que había surgido en la retaguardia republicana como producto del fracaso de la rebelión militar y de la movilización revolucionaria de partidos y sindicatos de izquierda. Esa situación revolucionaria dominada por las columnas milicianas y los comités locales fue desapareciendo a medida que el Estado republicano lograba integrar a los grupos de civiles armados en el nuevo Ejército Popular de la República y convertir los comités revolucionarios en consejos municipales. Un proceso militar y político que comenzó precisamente en los últimos meses de 1936 y que estará prácticamente culminado en los primeros de 1937. Como he dicho, la cronología deja poco espacio a la duda: la coincidencia en el tiempo de la progresiva desaparición de los poderes revolucionarios y la remisión significativa del volumen mensual de muertes violentas no puede ser una casualidad ${ }^{13}$.

12 Colaboración entre milicias y comités, en Casanova, 1999, pp. 136-139; Kalyvas, 2010, pp. 157-163; y Ledesma, 2010, p. 163.

13 La desaparición de milicianos y comités como dos de las razones fundamentales de la disminución de la violencia, en Casanova, 1999, p. 163. 


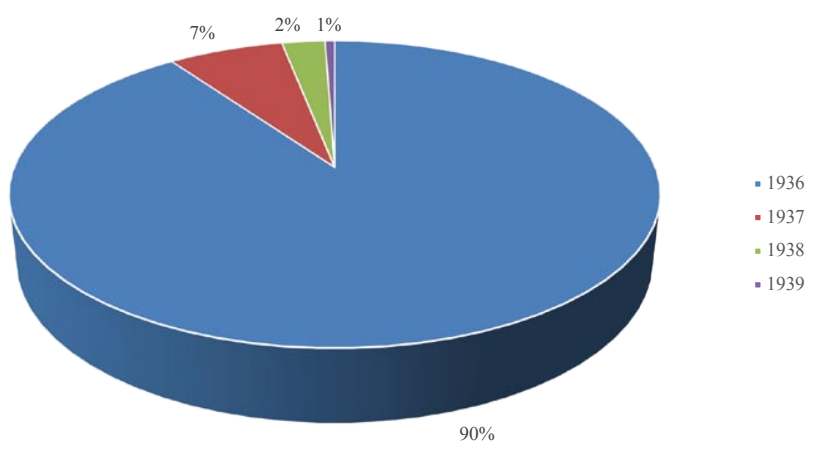

Gráfico 1

Víctimas de la violencia revolucionaria por años

Fuente: ver nota 3.

Las pruebas de la colaboración entre milicianos y comités son innegables, según señalaba antes. Dos son las principales. La primera es que buena parte de las víctimas de la violencia revolucionaria murió lejos de su lugar de residencia, lo que denota la intervención de agentes extraños a la comunidad en las acciones violentas. 463 personas, o lo que es lo mismo, cerca de dos tercios del total de víctimas, fueron asesinadas o ejecutadas tras cruzar los límites del término municipal en que residían habitualmente (cuadro 2). La segunda de las pruebas de la colaboración entre grupos de civiles armados y comités locales revolucionarios se encuentra en la filiación política de las víctimas y en los cargos públicos ocupados por las mismas durante las etapas políticas inmediatamente anteriores a la rebelión militar, hechos que señalan la participación necesaria de vecinos en la violencia desplegada sobre la comunidad. Primero, de las 394 personas muertas violentamente sobre las que existe información relativa a su adscripción ideológica, 232, es decir, cerca del 60 por 100 del total, eran derechistas, según la expresión utilizada por los funcionarios que elaboraron la Causa General; otras 100 , o sea, una cuarta parte, eran militantes, afiliados o simpatizantes de Falange Española; y 49 más, otro 10 por 100 largo, pertenecían o estaban vinculadas a las organizaciones del catolicismo social y político (cuadro 3). Segundo, entre las 709 víctimas de la violencia política figuran 97 personas que habían desempeñado o desempeñaban cargos públicos. Había 35 alcaldes, 30 concejales, 15 secretarios de ayuntamiento y 17 jueces. 


\section{Cuadro 2}

Víctimas que no murieron en su municipio distribuidas por el lugar de residencia por partidos judiciales

\begin{tabular}{lccc}
\hline \multicolumn{1}{c}{ Partidos judiciales } & Víctimas & Total & Porcentaje \\
\hline Atienza & 14 & 20 & 70,00 \\
Brihuega & 57 & 74 & 77,03 \\
Cifuentes & 21 & 39 & 53,85 \\
Cogolludo & 37 & 56 & 66,07 \\
Guadalajara & 84 & 195 & 43,08 \\
Molina de Aragón & 6 & 8 & 75,00 \\
Pastrana & 132 & 152 & 86,84 \\
Sacedón & 82 & 98 & 83,67 \\
Sigüenza & 30 & 67 & 44,78 \\
\hline Total & 463 & 709 & 65,30 \\
\hline
\end{tabular}

Fuente: ver nota 3.

\section{Cuadro 3}

Víctimas de la violencia revolucionaria en la provincia de Guadalajara por filiación política

\begin{tabular}{lrc}
\hline \multicolumn{1}{c}{ Filiación política } & Total & $\%$ \\
\hline Falange Española & 100 & 14,10 \\
Comunión Tradicionalista & 3 & 0,42 \\
Renovación Española y monárquicos & 2 & 0,28 \\
CEDA/Acción Popular/JAP & 46 & 6,49 \\
Acción Católica & 3 & 0,42 \\
Derechistas & 232 & 32,72 \\
Romanonistas & 1 & 0,14 \\
Partido Republicano Radical & 1 & 0,14 \\
Republicanos & 1 & 0,14 \\
Frente Popular & 1 & 0,14 \\
Izquierdistas & 3 & 0,42 \\
UGT & 1 & 0,14 \\
Desconocida & 315 & 44,43 \\
\hline Total & 709 & 100,00 \\
\hline
\end{tabular}

Fuente: ver nota 3. 
Las evidencias de que los comités locales jugaron un papel de mayor importancia en el proceso de la violencia política también son de difícil discusión. Las principales son dos. Y ambas están relacionadas con la distribución espacial de las víctimas de esa violencia. Prácticamente la mitad de las personas que perdieron la vida violentamente residía en municipios de los partidos de Guadalajara y Pastrana, situados en la zona suroccidental de la provincia. En un segundo plano aparecen los partidos de Sacedón, Brihuega, Sigüenza, Cogolludo y Cifuentes, que conjuntamente arrojaron casi en su totalidad la mitad restante de las muertes violentas y que extendieron la zona de mayor impacto de la violencia política hacia el norte y el este. En fin, los partidos que contabilizaron un menor número de víctimas de esa violencia fueron los de Atienza y Molina, que radicaban en los extremos septentrional y oriental del territorio y que estuvieron ocupados parcialmente por los rebeldes desde el principio de la guerra (mapa 2). Al relacionar la cantidad de muertes violentas con el número de habitantes de cada partido judicial en 1930 el panorama ofrecido por el volumen de víctimas adquiere mayor precisión. La intensidad de la violencia política, en efecto, fue también mayor en la parte suroccidental de la provincia, aunque desde esta perspectiva es el partido de Sacedón el territorio que encabeza la lista, seguido muy de cerca por los de Guadalajara y Pastrana. Mucho menor fue la intensidad de esa violencia en los partidos de Brihuega, Cogolludo, Sigüenza y Cifuentes. Las zonas en las que esa intensidad fue mínima fueron los partidos de Atienza y, sobre todo, Molina (mapa 3) ${ }^{14}$.

${ }^{14}$ El número de habitantes, en Presidencia del Consejo de Ministros, 1932, tomo I, pp. $115-126$ y 342 . 


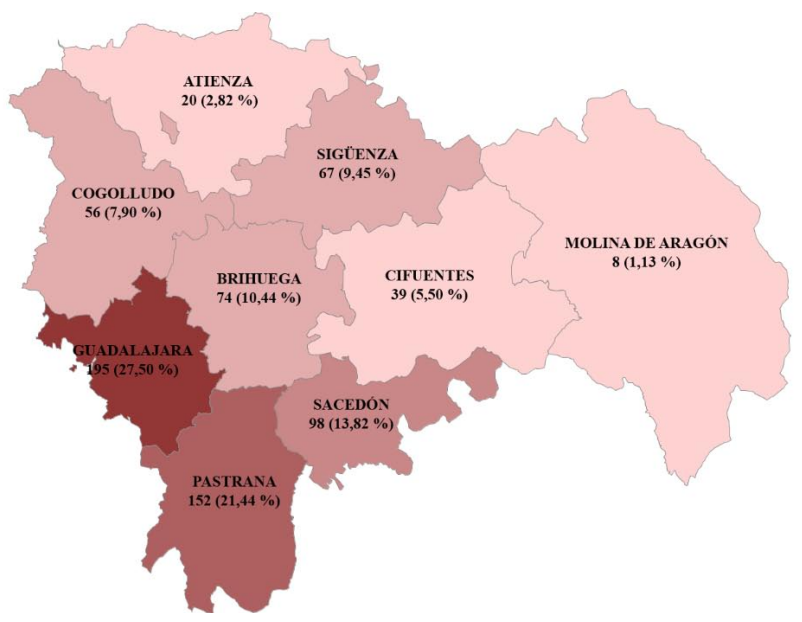

\section{Mapa 2}

Víctimas de la violencia revolucionaria por partidos judiciales

Fuente: ver nota 3.

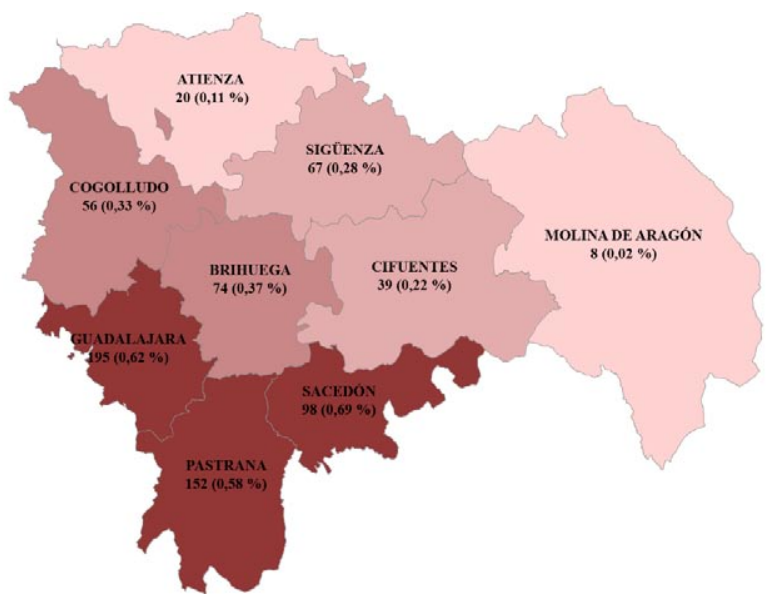

Mapa 3

Población muerta por la violencia revolucionaria por partidos judiciales

Fuente: ver nota 3. 
La primera de las evidencias de que la intervención de los comités locales en el proceso de la violencia política fue mayor que la de los grupos de milicianos se encuentra en la relación existente entre la geografía de la violencia y la geografía de los poderes. Porque lo cierto es que aquellas zonas en que mayor fue el volumen y la intensidad de la violencia no coincidían con las áreas en que operaban las columnas milicianas, es decir, las que recorría la línea del frente, sino con las situadas lejos de la misma, en el cuadrante suroeste de la provincia, que era donde la red de comités poseía un mayor espesor, tanto en términos absolutos como en términos relativos. En efecto, 42 de los 55 comités locales cuya existencia está documentada, es decir, más del 75 por 100 del total, funcionaban en municipios de los distritos de Sacedón, Pastrana, Brihuega y Guadalajara, que son, precisamente, los partidos en que mayor era el porcentaje de municipios con comité sobre el total: primero estaba Sacedón, con casi el 60 por 100; luego, Pastrana, con más del 40 por 100; después, Guadalajara, con el 25; y, finalmente, Brihuega, con el 16 por 100; ningún otro territorio de la provincia llegaba siquiera al 10 por 100 (mapas 4 y 5) ${ }^{15}$.

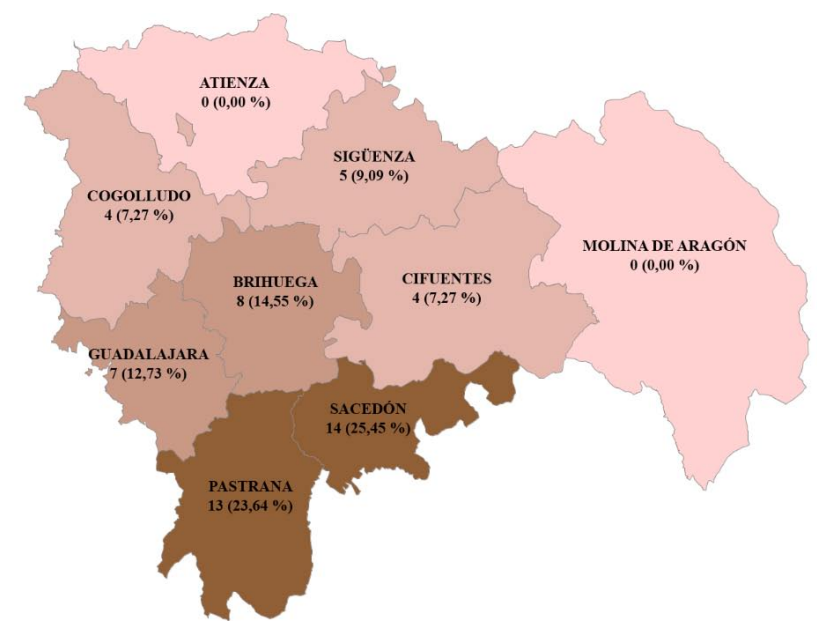

Mapa 4

Municipios con comité revolucionario por partidos judiciales

Fuente: ver nota 11.

15 Una advertencia acerca de la naturaleza de la información sobre los comités, en Martín Nieto, 2014, nota 10. 


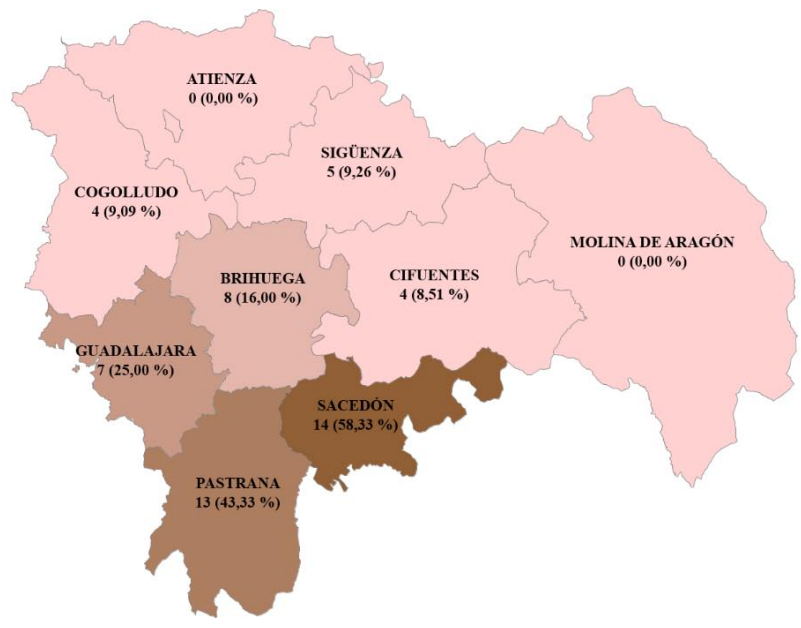

Mapa 5

Proporción de municipios con comité revolucionario por partidos judiciales

Fuente: ver nota 11.

La segunda de las evidencias de que los comités adquirieron mayor responsabilidad en la violencia política se halla en la distribución espacial de las víctimas que fueron asesinadas o ejecutadas lejos del hogar. Y es que esa geografía cuestiona que fueran los grupos de civiles armados los únicos que contaban con capacidad suficiente para trasladar a las futuras víctimas de una localidad a otra. Primero, porque la mayor parte de las víctimas de la violencia que murieron fuera de su municipio de residencia habitaba la zona suroccidental de la provincia, y segundo, porque la mayoría de ese tipo de víctimas falleció en esa misma parte del territorio. Es decir, que el origen y el destino de estos viajes mortales coincidían entre sí y correspondían a su vez con el área donde mayor volumen y espesor alcanzó la red de comités locales y donde menor presencia poseían las unidades militares de civiles armados, concentradas en torno a la línea del frente, más al noreste. Nada menos que 355 de las 463 víctimas de esta clase, más de las tres cuartas partes del total, eran vecinos de municipios pertenecientes a los partidos de Pastrana, Guadalajara, Sacedón y Brihuega. Y en estos distritos fue, precisamente, donde falleció cerca del 70 por 100 de las víctimas de este tipo, 321 personas concretamente. 
En los comités locales había de todo. Había socialistas, comunistas y anarquistas, por supuesto. Pero también republicanos. La UGT era, sin lugar a dudas, la organización que contaba con una mayor cuota de poder en ese enjambre de poderes revolucionarios. Contaba con representantes en los comités de 39 de los 55 municipios con comité que hubo en la provincia. Además, en 23 de esos 39 municipios el comité estaba compuesto exclusivamente por militantes de la UGT. Ninguna otra organización política o sindical podía competir ni de lejos con semejante poder. Los comunistas estaban representados en los comités de nueve municipios, los anarquistas en los de ocho y los republicanos solo en los de tres. Por si fuera poco, a la cifra de comités con militantes de la UGT entre sus miembros habría que sumar la de comités con representantes del PSOE, con lo que el poder de los socialistas alcanzaría a nada menos que a 41 de los $55 \mathrm{mu}-$ nicipios con comité de la provincia, o sea, a casi un 75 por 100 del total (cuadro 4). Fueron los socialistas, por tanto, los principales responsables de la violencia política desplegada en esta provincia, una certeza que queda confirmada al observar la relación existente en los partidos de la zona suroccidental del territorio, la zona donde mayor volumen e intensidad adquirió esa violencia, entre municipios en que funcionaba un comité con al menos un representante de la UGT o el PSOE y el total de municipios con comité. Porque en Sacedón y Guadalajara esa relación supera el 85 por 100, en Brihuega alcanza el 75 y en Pastrana está cerca del 70.

\section{Cuadro 4}

Representación de partidos y sindicatos en los comités revolucionarios por organización

\begin{tabular}{lcc}
\hline \multicolumn{1}{c}{ Organización } & Comités & $\%$ \\
\hline UGT & 39 & 70,91 \\
CNT/FAI/JJLL & 8 & 14,55 \\
PCE & 8 & 14,55 \\
PSOE & 5 & 9,09 \\
Izquierda Republicana & 3 & 5,45 \\
Unión Republicana & 1 & 1,82 \\
JSU & 1 & 1,82 \\
Desconocida & 9 & 16,36 \\
\hline
\end{tabular}

Fuente: ver nota 11 . 
Los socialistas eran asimismo el grupo político que poseía una mayor cuota de poder entre los grupos de civiles armados que operaron en esta provincia durante los seis primeros meses de guerra. Participaron en el reclutamiento y la organización de la columna de Jesús Martínez Aragón, de las Milicias Aragonesas y de la columna del teniente coronel Víctor Lacalle. Eso, entre las unidades que participaron en la lucha desde la misma derrota de la rebelión. En noviembre de 1936 había en la provincia cuatro formaciones tras las que estaban los socialistas. Eran los batallones Pablo Iglesias, Alicante Rojo, 20 de Julio y Numancia. Los comunistas también habían participado en el alistamiento y el encuadramiento de la columna de Martínez Aragón y es probable que también en los de la columna de Lacalle. Meses después los comunistas eran responsables de los batallones Alicante Rojo y Pasionaria y de las Milicias Antifascistas de Guadalajara. Los republicanos tomaron parte asimismo en el reclutamiento y la organización de las Milicias Aragonesas, la columna de Lacalle y el Batallón Numancia. Las dos primeras unidades estaban vinculadas a Izquierda Republicana y la tercera, a Unión Republicana. El POUM, por su parte, había enviado a las Milicias de la Juventud, otro de los grupos armados que luchaba en esta provincia desde el principio de la guerra. Los anarquistas, en fin, también habían mandado solo una columna a este territorio. De hecho, el de los anarquistas era el grupo de milicianos que participó en la derrota de la rebelión de los militares y los guardias civiles en la capital provincial a las órdenes del coronel Puigdengolas. El batallón de la CNT permaneció en esta provincia hasta octubre, cuando fue prácticamente destruido por las tropas insurrectas en Sigüenza ${ }^{16}$.

16 La evolución global de las fuerzas armadas republicanas y el desarrollo general de las operaciones bélicas, en Salas Larrazábal, 1973, vol. I, pp. 248-251, 659, 664, 668671 y 871; y Camarena Merino, 2000, pp. 121-124 y 126-129. Martínez Aragón y Milicias de la Juventud, en Manrique, 2009, pp. 20 y 22; y Sequera Martínez, 2007, p. 22. Milicias Aragonesas, en Salas Larrazábal, 1973, vol. I, p. 249; y Hernández de León Portilla, 2004, pp. 249-250. Lacalle y Pablo Iglesias, en AHN. CG, legajo 1.530, exp. 7, declaraciones de Gregorio García Sánchez, f. 33; Ángel de la Orden Díaz, f. 40; y Domingo Mármol Prato, f. 259. Los grupos que había en la provincia en noviembre, en un estado de situación de fuerzas incompleto y sin fecha que puede ser datado en la segunda mitad de dicho mes conservado en Archivo General Militar de Ávila. Zona Roja, rollo 96, armario 97, legajo 953, carpeta 9, documento 2, ff. 105 y 107 (este documento fue confundido con otro en Martín Nieto, 2014, nota 14). Alicante Rojo, en Ruiz, Arturo, «Cartas desde el Batallón Rojo», El País, 5 de enero de 2009; y Etchebéhère, 2003, p. 132. 20 de julio, en la entrada de Gabriel Carvajal Alcaide, militante del Sindicato 


\section{Conclusiones}

Las conclusiones a las que es posible llegar tras este recorrido por la secuencia de acciones colectivas protagonizadas por los diversos actores sociales y políticos de la provincia de Guadalajara a lo largo de 1936 permiten poner en cuestión algunos de los argumentos que ciertos historiadores manejan a la hora de analizar la violencia política y social durante la primavera del Frente Popular y la guerra civil. En primer lugar, es obvio que esa violencia no fue un factor determinante del proceso político de la provincia durante los primeros seis meses y medio del año. Las cifras de víctimas mortales de la violencia entre las elecciones de febrero y el golpe de julio son muy elocuentes al respecto. Guadalajara, con solo tres muertes violentas, figuró en el grupo de provincias en el que falleció menos de un 1 por 100 del total de víctimas que hubo en todo el país durante esa etapa, que fue de 384 . El relato de la constitución de comités del Frente Popular, de las huelgas industriales y agrarias y de las manifestaciones, las concentraciones y los mítines que tuvieron lugar en la primera mitad de 1936 que ha ocupado buena parte de este trabajo también es muy significativo. Apunta con claridad a que los actores sociales y políticos de esta provincia prefirieron por lo general formas de acción pacíficas ${ }^{17}$.

En segundo lugar, resulta evidente que no hubo continuidad entre las violencias de antes y de después de julio. No la hubo a nivel cuantitativo. Durante los primeros seis meses y medio de 1936 la violencia sociopolítica causó cuatro víctimas mortales en toda la provincia; cuando terminó el mes de julio, habiendo transcurrido solo diez días desde la derrota del golpe militar en la capital provincial, las muertes violentas ascendían ya a 71 (gráfico 2). No hubo continuidad entre los actores de esas violencias. Si durante el verano y el otoño de 1936 los que asesinaban y ejecutaban eran, sobre todo, los socialistas,

de Artes Blancas, en el Diccionario Biográfico del Socialismo Español (disponible en http://www.fpabloiglesias.es/archivo-y-biblioteca/diccionario-biografico [6 de agosto de 2020]) . Numancia, en Berzal de la Rosa, 2004, p. 298. Pasionaria, en Camarena Merino, 2000, pp. 122-124; Sequera Martínez, 2007, pp. 30 y 45; y Manrique, 2009, p. 41. Milicias Antifascistas de Guadalajara, en Valle Calzado, Villena Espinosa y Sánchez Sánchez, 1993, p. 126. CNT, en Salas Larrazábal, 1973, vol. I, pp. 659-660 y 662; y Mera, 1976 , pp. 55-72, 98-104 у 115.

17 384, en González Calleja, 2015, p. 271. 
parece ser que durante el invierno, la primavera y la primera parte del verano los victimarios no eran izquierdistas, sino individuos o grupos de ideología conservadora o reaccionaria. Esto significa varias cosas. La primera es que la violencia de la primera mitad del año no explica el apoyo de las clases medias urbanas y rurales a la conspiración y la rebelión militares, como podría sostenerse si esos sectores sociales hubieran sido el objetivo de las acciones violentas. La segunda es que esa violencia no fue causa de la guerra civil, pues los responsables de las acciones violentas previas a la sublevación militar y los grupos políticos que estaban detrás de la conspiración en que dicha sublevación tuvo su origen eran exactamente los mismos: en el caso de esta provincia, católicos y falangistas. Y la tercera es que la violencia posterior al golpe de Estado fallido no fue ni la culminación ni la consecuencia de las prácticas violentas anteriores al mismo. Y no lo fue, sencillamente, porque esas violencias, como he dicho, estuvieron protagonizadas por distintos actores.

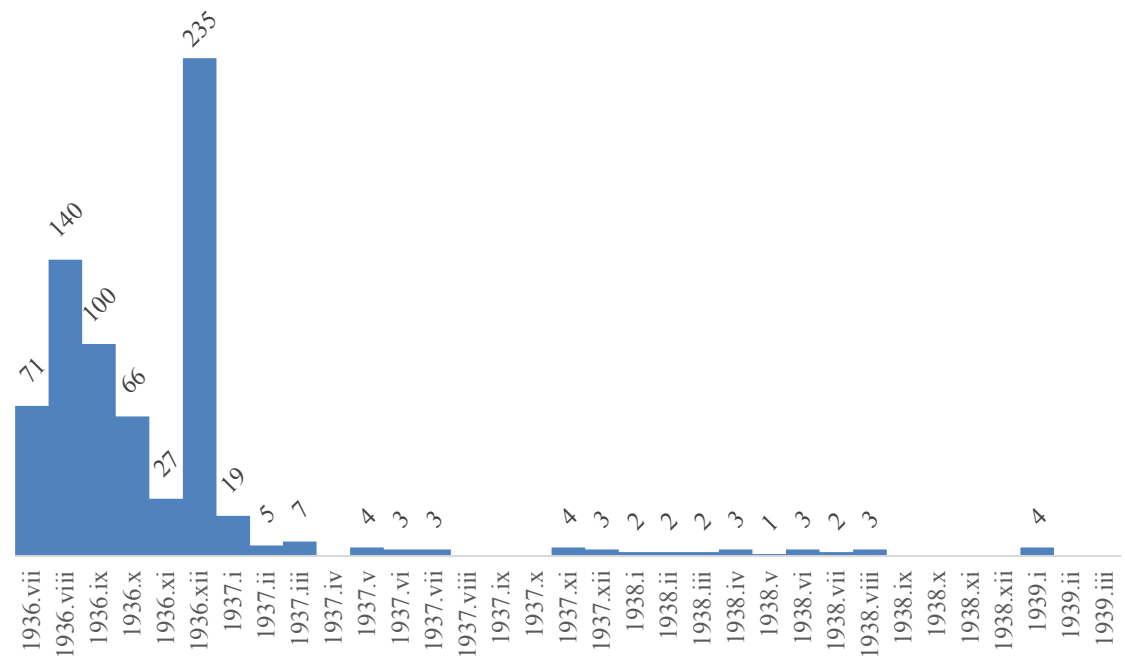

Gráfico 2

Víctimas de la violencia revolucionaria por meses

Fuente: ver nota 3. 
Tampoco hubo continuidad entre la violencia de antes y de después del golpe en lo que respecta a los espacios en que tuvo lugar. Es cierto que tres de las cuatro víctimas que hubo durante los seis primeros meses del año eran vecinos de municipios incardinados en los partidos judiciales que formaban el suroeste provincial, es decir, la zona donde mayor volumen e intensidad adquirió la violencia política después de julio. Y es cierto que la cuarta residía en Sigüenza, cabeza de otro de los partidos que peor parados salieron del proceso revolucionario que sucedió a la rebelión militar. Pero también es innegable que el fracaso parcial de esa rebelión y la consiguiente movilización de los partidos y sindicatos de izquierda inauguró una situación revolucionaria en el marco de la cual las prácticas violentas conocieron una generalizada expansión por la geografía provincial, alcanzando puntos del territorio que, antes de la insurrección militar, no habían sido testigos de ningún tipo de violencia. En otras palabras, la inmensa mayoría de los municipios que fueron escenario de asesinatos y ejecuciones tras la neutralización de la rebelión militar no había sido escenario de ni un solo episodio de violencia entre enero y julio.

La continuidad entre las violencias anterior y posterior a la sublevación militar también brilló por su ausencia, al fin, en lo relativo a las formas de las acciones violentas. Y es que los choques violentos entre grupos de vecinos y los atentados personales de antes de julio eran claramente distintos a los asesinatos, las ejecuciones, los paseos y las sacas de después. Ni que decir tiene que, por lo general, la violencia anterior al golpe de Estado estaba bastante desorganizada y descoordinada, no como la posterior al mismo, que estaba relativamente bien organizada y conocía un grado de coordinación nada desdeñable. La primera era el fruto o bien de encuentros fortuitos entre un conjunto mayor o menor de vecinos de una población, como en Auñón y Moratilla, o bien de iniciativas de pequeños grupos de individuos, como en Guadalajara capital y Sigüenza. La segunda, por el contrario, era, en su mayor parte, el resultado de una estrategia política que las diversas organizaciones políticas y sindicales de la izquierda burguesa y obrera impulsaron desde las columnas milicianas y los comités locales surgidos tras la derrota de la rebelión militar. Columnas y comités que, como más arriba quedó apuntado, ejercieron la violencia de forma coordinada. Pero esta coordinación no funcionó sólo entre unidades militares y comités revolucionarios. De hecho, existen pruebas de que era precisamente dentro de la red que formaban dichos comités locales donde mayor era el nivel de coordinación. Incluso es posible encontrar un indicador de que en el interior de esa red existía una cierta jerarquía entre el Comité del Frente Popular de la ciu- 
dad de Guadalajara, por un lado, y el resto de comités de enlace, por otro. No otra cosa parece señalar el hecho de que más del 40 por 100 de las víctimas de la violencia que murieron fuera de su municipio de residencia terminaran sus días en la capital de la provincia.

En tercer y último lugar, el análisis de la violencia política posterior a julio en relación con la movilización sociopolítica anterior a esa fecha señala que las prácticas violentas del verano y el otoño de 1936 no respondían solo a la conflictividad social y política anterior, sino, sobre todo, a una estrategia política determinada. Porque es innegable que existen conexiones entre las acciones colectivas de antes y de después de la sublevación militar. Los actores coinciden: comunistas, republicanos y, sobre todo, socialistas fueron los responsables principales tanto de las movilizaciones de la primera mitad del año como de las de la segunda. Los espacios de unas y de otras también coinciden: el suroeste provincial fue el escenario tanto de la mayor parte de la conflictividad previa a la guerra, en este caso, junto al noreste, que enseguida cayó bajo el control de las tropas rebeldes, como de la mayor parte de la violencia política posterior a la rebelión militar. Y existe asimismo una cierta relación entre las estructuras organizativas utilizadas por los revolucionarios para ejercer su acción durante la guerra y las que los partidos y sindicatos de izquierda utilizaron durante el invierno, la primavera y las primeras semanas del verano: los comités locales del Frente Popular, que pretendían coordinar la acción social y política de republicanos, socialistas y comunistas antes de la guerra, en los que resulta difícil no identificar un significativo precedente de los comités de enlace revolucionarios, utilizados por esos mismos grupos políticos y sindicales para desarrollar sus acciones violentas. De hecho, era frecuente que entre el comité revolucionario y el comité del Frente Popular no existiera solución de continuidad ${ }^{18}$.

Pero esas conexiones no sirven por sí solas para explicar la violencia política desarrollada en la retaguardia republicana de la provincia. Es decir, que la conflictividad previa no deja de ser uno solo de los varios factores que explican esa violencia. Existen otros, quizá todavía de mayor importancia, como la oportunidad política brindada por la situación de soberanía múltiple creada por la rebelión y la revolución; la cultura política de naturaleza excluyente y violenta que los actores de la izquierda burguesa y obrera compartían; la disponibilidad de recursos materiales, como las armas, y organizativos, como los

18 Comités locales del Frente Popular, en 7 de marzo, p. 1; 21 de marzo, pp. 1 y 4; 28 de marzo, pp. 1 y $2 ; 4$ de abril, p. $1 ; 2$ de mayo, pp. 1 y 4; 23 de mayo, p. 3; y Díez Torre, 1983, pp. 150-151. 
comités; y la estrategia política de naturaleza revolucionaria que conformaba las agendas de los diversos partidos y sindicatos. De estos factores, sin embargo, solo el último me parece decisivo para explicar la violencia sociopolítica posterior a julio. Los grupos políticos y sindicales de izquierda asesinaron y ejecutaron no porque la nueva estructura de oportunidades políticas lo permitiera, porque su cultura política lo dictara, porque dispusieran de armas o porque estuvieran organizados en comités, sino, ante todo porque optaron por incluir las prácticas violentas en su repertorio de acciones colectivas, porque decidieron utilizar la violencia para construir y consolidar sus espacios de poder y porque eligieron colocar la eliminación del enemigo político y social en el centro de su estrategia política. Y así fue. Por eso el blanco predilecto de las acciones violentas fueron los labradores de ideología conservadora o reaccionaria, según el perfil social y político de las víctimas (cuadros 5 y 6). Y por eso la violencia mostró mayor volumen e intensidad en la zona suroccidental de la provincia, la misma donde estaba concentrada la mayor parte de la población derechista, según la geografía del voto en las elecciones de febrero (mapas 2, 3 y 6). En definitiva, los partidos y sindicatos de la izquierda burguesa y obrera asesinaron y ejecutaron no porque estuvieran determinados a hacerlo, sino porque eso fue lo que decidieron hacer.

\section{Cuadro 5}

Víctimas de la violencia revolucionaria por grupos sociales y profesionales

\begin{tabular}{lrr}
\hline \multicolumn{1}{c}{ Grupos sociales y profesionales } & Total & $\%$ \\
\hline Propietarios y labradores & 242 & 34,13 \\
Comerciantes e industriales & 71 & 10,01 \\
Profesionales liberales & 98 & 13,82 \\
Obreros y empleados & 55 & 7,76 \\
Jornaleros & 35 & 4,94 \\
Militares y guardias civiles & 60 & 8,46 \\
Religiosos & 109 & 15,37 \\
S.L. & 16 & 2,26 \\
Otras & 3 & 0,42 \\
Desconocida & 20 & 2,82 \\
\hline Total & 709 & 100,00 \\
\hline
\end{tabular}

Fuente: ver nota 3. 


\section{Cuadro 6}

Labradores muertos por la violencia revolucionaria por filiación política

\begin{tabular}{lrr}
\hline \multicolumn{1}{c}{ Filiación política } & Total & $\%$ \\
\hline Falange Española & 46 & 19,01 \\
Renovación Española y monárquicos & 1 & 0,41 \\
CEDA/Acción Popular/JAP & 19 & 7,85 \\
Derechistas & 121 & 50,00 \\
Romanonistas & 1 & 0,41 \\
Frente Popular & 1 & 0,41 \\
Desconocida & 53 & 21,90 \\
\hline Total & 242 & 100,00 \\
\hline
\end{tabular}

Fuente: ver nota 3 .

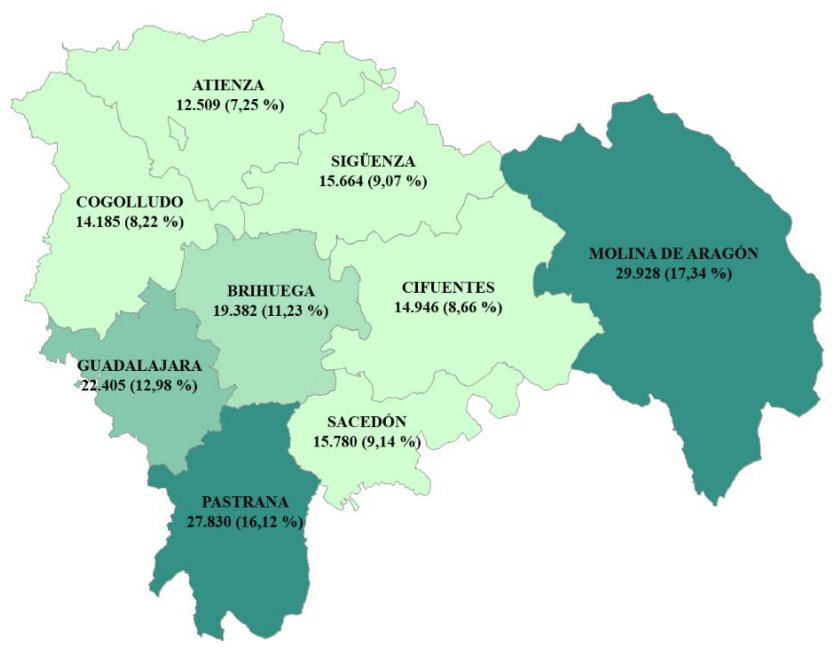

Mapa 6

Voto derechista en las elecciones de febrero de 1936 por partidos judiciales

Fuente: Boletín Oficial de la Provincia de Guadalajara, 24 de febrero de 1936, pp. 3-10. 


\section{Fuentes}

Archivo General Militar de Ávila

Archivo Histórico Nacional

Biblioteca Virtual de Prensa Histórica

Instituto Nacional de Estadística

\section{Bibliografía}

Álvarez TARdío, Manuel, «The Impact of Political Violence During the Spanish General Election of 1936», Journal of Contemporary History, 48, 3, 2013, pp. 463-485.

Álvarez TARDío, Manuel y Villa GarcíA, Roberto, «El impacto de la violencia anticlerical en la primavera de 1936 y la respuesta de las autoridades», Hispania Sacra, LXV, 132, 2013, pp. 683-764.

BERZAL DE LA ROSA, Enrique, «Represión y resistencia (1936-1939)», en REDERO SAn Román, Manuel (coord.), La Unión General de Trabajadores en Castilla y León (1888-1998). Historia de un compromiso social, Salamanca, Universidad de Salamanca, 2004, pp. 253-306.

CAmarena Merino, Vicente, «Guadalajara, sesenta y tres años después...», en Ortiz Heras, Manuel (coord.), La Guerra Civil en Castilla-La Mancha. De El Alcázar a Los Llanos, Madrid, Celeste, 2000, pp. 111-137.

CASANOVA, Julián, «Rebelión y revolución», en JULIÁ, Santos (coord.), Víctimas de la guerra civil, Madrid, Temas de Hoy, 1999, pp. 57-186.

Diccionario Biográfico del Socialismo Español. Disponible en http://www.fpabloiglesias.es/archivo-y-biblioteca/diccionario-biografico [6 de agosto de 2020].

DíEz TORRE, Alejandro R., «Guadalajara, 1936: la primera crisis del caciquismo», Wad-al-Hayara, 10, 1983, pp. 137-164.

DíEz TORRE, Alejandro R., «Del caciquismo a la colectivización: el desarrollo histórico de las colectividades de Guadalajara, 1936-1939», Wad-al-Hayara, 11, 1984, pp. 175-226.

EtCHebÉHÈre, Mika, Mi guerra de España. Testimonio de una miliciana al mando de una columna del POUM, Barcelona, Alikornio Ediciones, 2003.

GonZÁlez CAlleja, Eduardo, Cifras cruentas. Las víctimas mortales de la violencia sociopolítica en la Segunda República española (1931-1936), Granada, Comares, 2015.

Hernández de León Portilla, Ascensión, España desde México. Vida y testimonio de transterrados, Madrid, Algaba, 2004.

Kalyvas, Stathis N., La lógica de la violencia en la guerra civil, Madrid, Akal, 2010 [2006]. 
LEDESMA, José Luis, «Una retaguardia al rojo. Las violencias en la zona republicana», en EsPinosA, Francisco (ed.), Violencia roja y azul. España, 19361950, Barcelona, Crítica, 2010, pp. 152-250.

LEDESMA, José Luis, «La «primavera trágica» de 1936 y la pendiente hacia la guerra civil», en SÁNCHEZ PÉREZ, Francisco (coord.), Los mitos del 18 de julio, Barcelona, Crítica, 2013, pp. 313-339.

Macadam, Doug, Maccarthy, John D. y ZALD, Mayer N. (eds.), Movimientos sociales: perspectivas comparadas. Oportunidades políticas, estructuras de movilización y marcos interpretativos culturales, Madrid, Istmo, 1999.

ManRIQue, José María, Sangre en la Alcarria. Sigüenza en la Guerra (19361939), Valladolid, Galland Books, 2009.

MARTín Nieto, Isaac, «Muerte en la Alcarria. Violencia revolucionaria y anarquismo en Guadalajara durante la guerra civil española (1936-1939)», $R e$ vista Universitaria de Historia Militar, 3, 6, 2014, pp. 28-53.

Mera, Cipriano, Guerra, exilio y cárcel de un anarcosindicalista, París, Ruedo Ibérico, 1976.

OrTIZ HeRAs, Manuel, «Terror y violencia política en Castilla-La Mancha», en Alía Miranda, Francisco y Valle Calzado, Ángel Ramón del (coords.), La Guerra Civil en Castilla-La Mancha, 70 años después. Actas del Congreso Internacional, Cuenca, Universidad de Castilla-La Mancha, 2008, pp. 1373-1401.

Presidencia del Consejo de Ministros, Censo de la Población de España, 1930, tomo I, Madrid, Talleres del Instituto Geográfico y Catastral, 1932.

Requena Gallego, Manuel, «La clase política y las contiendas electorales en las provincias de Castilla-La Mancha, 1931-1933», en I Congreso de Historia de Castilla-La Mancha. Tomo X. Transformaciones burguesas, cambios políticos y evolución social (2), Toledo, Junta de Comunidades de Castilla-La Mancha, 1988, pp. 15-37.

Salas Larrazábal, Ramón, Historia del Ejército Popular de la República, 4 vols., Madrid, Editora Nacional, 1973.

Salas LarrazÁbal, Ramón, Pérdidas de la guerra, Barcelona, Planeta, 1977.

Sequera Martínez, Luis de, «Una aproximación a la batalla de Sigüenza», $R e$ vista de historia militar, 102, 2007, pp. 11-66.

TARROW, Sidney, El poder en movimiento. Los movimientos sociales, la acción colectiva y la política, Madrid, Alianza, 1997 [1994]

Valle Calzado, Ángel Ramón del, Villena Espinosa, Rafael y Sánchez SÁNCHEZ, Isidro, «La prensa, una fuente para el estudio de la Guerra Civil en Castilla-La Mancha», en SÁnchez SÁnchez, Isidro, OrTIZ Heras, Manuel y RuIZ GonZÁlez, David (coords.), España franquista. Causa general y actitudes sociales ante la dictadura, Albacete, Universidad de Castilla-La Mancha, 1993, pp. 117-137. 


\section{Financiación}

Miembro del Grupo HISTAGRA (Historia Agraria e Política do Mundo Rural. Séculos XIX e XX, GI1657) del Sistema Universitario de Galicia. La investigación que hay detrás de este artículo fue realizada bajo el amparo de una Ayuda para la Formación de Personal Investigador de la Universidad de Salamanca (2009-2013) y del Proyecto de Investigación «La violencia política de 1936 y el 18 de julio como punto de ruptura. Un análisis micro», financiado por el Ministerio de Economía y Competitividad y por el Fondo Europeo de Desarrollo Regional, 2016-2020 (HAR2015-65115-P).

\section{Datos del autor}

Isaac Martín Nieto (Villanueva de la Serena, Badajoz, 1986) es Investigador posdoctoral de la Xunta de Galicia en la Universidade de Santiago de Compostela y miembro del Grupo HISTAGRA (Historia Agraria e Política do Mundo Rural. Séculos XIX e XX). Doctor en Historia por la Universidad de Salamanca, ha sido profesor asociado en el Departamento de Historia Medieval, Moderna y Contemporánea de esa misma universidad, donde disfrutó de una Ayuda para la Formación de Personal Investigador. Ha publicado varios libros, artículos y capítulos de libro y ha participado en numerosos congresos y seminarios nacionales e internacionales. Sus líneas de investigación comprenden el movimiento libertario, el cooperativismo agrario y la violencia política. 